\title{
DDEECONOMIAE 竧AGRONEGÓCIO
}

ISSN impresso: 1679-1614

ISSN online: $2526-5539$

Vol. 18 | N. 3 | 2020

EDITORIAL

\section{AMAZÔNIA: MANTER A FLORESTA EM PÉ OU PLANTAR?}

\author{
Alfredo Kingo Oyama Homma* \\ ORCID: 0000-0003-0330-9858 \\ E-mail: alfredo.homma@embrapa.br
}

(*) Empresa Brasileira de Pesquisa Agropecuária - Embrapa Amazônia Oriental, Universidade do Estado do Pará, Belém, Pará, Brasil

\section{Introdução}

Cursei o Doutorado em Economia Rural na Universidade Federal de Viçosa no período 1984 a 1987, orientado pelo Prof. Antônio Raphael Teixeira Filho, seguindo a sequência da graduação em agronomia (1970) e Mestrado em Economia Rural (1976).

Efetuei a defesa do Projeto "A Extração de Recursos Naturais Renováveis: o Caso do Extrativismo Vegetal na Amazônia", no dia 27 de outubro de 1987, no qual participaram os Professor(a)es Fátima Marília Andrade de Carvalho, João Eustáquio Lima, Matheus Bressan e Sonia Coelho de Alvarenga. No dia 10 de novembro de 1987 apresentei o Seminário de Tese para cumprir os requisitos do curso de doutorado e foi pouco compreendido.

Defendi a tese na tarde do dia 25 de novembro de 1988. Faziam parte da Banca os professores Antônio Raphael Teixeira Filho, Carlos Antônio Moreira Leite, Edson Potsch Magalhães (1914-2008), Fernando Antônio da Silveira Rocha (1938-1999) e Sônia Coelho de Alvarenga. Menos de um mês após a defesa, no dia 22 de dezembro de 1988 ocorreu em Xapuri, Acre, o assassinato do líder sindical Francisco Alves Mendes Filho que ficou mundialmente conhecido como Chico Mentes (1944-1988) (HOMMA, 1989).

$\mathrm{Na}$ época os textos sobre o extrativismo vegetal no país e no mundo tinha um interesse estritamente local ou regional. Com o assassinato de Chico Mendes o extrativismo vegetal ganhou relevância para a comunidade acadêmica, ONGs e para a mídia nacional e mundial. O problema é que os resultados da minha tese eram contrários do que pregavam e defendiam os ambientalistas. 
Os ambientalistas perceberam a importância política do extrativismo vegetal na Amazônia, a apologia da "floresta em pé", aqui entendido como extrativismo vegetal, para frear o desmatamento e as queimadas e gerar renda. No período de 12 a 16 de setembro de 1988, Mary Helena Allegretti organizou em Curitiba, o $1^{\circ}$ Seminário Planejamento e Gestão do Processo de Criação de Reservas Extrativistas na Amazônia, o primeiro evento técnico sobre o tema (ALLEGRETTI et al., 2018; ALMEIDA et al., 2018).

$\mathrm{Na}$ ocasião cursava o doutorado e ela soube que eu trabalhava com extrativismo vegetal e convidou-me para proferir uma palestra. Suspeito que a indicação tenha partido de Peter Hermann May (UFRRJ), que utilizou meus trabalhos sobre extrativismo vegetal como argumento teórico para a sua tese de doutorado na Cornell University (MAY, 1986). Foi a tese de Peter May que deu credibilidade para viabilizar o meu Projeto de Pesquisa na UFV. Proferi a palestra referente a minha tese de doutorado que estava concluindo. Foi lá que conheci Chico Mendes, uma pessoa cordial, que teve de retornar às pressas para o Acre por problemas relacionados a empates ${ }^{1}$ e foi assassinado três meses e uma semana depois.

Na edição de 19 de dezembro de 1990 da Revista Veja, publiquei o artigo "Deixem Chico Mendes em Paz", no Ponto de Vista, cuja tiragem foi de 800 mil exemplares, comentando sobre as limitações do extrativismo vegetal e teve uma ampla repercussão nacional e mundial (HOMMA, 1990). Propositadamente, a Revista Veja deixou concluir o julgamento do assassinato de Chico Mendes, em 15/12/1990 (sábado) para divulgar o artigo. Recebi cumprimentos de governadores, ministro, senadores, deputados, jornalistas, superintendentes, organizações de produtores, etc., e, contrárias. A própria revista ao comunicar a aprovação do artigo, seis meses antes, comentou: "você vai arrumar muitos inimigos mas também grandes amigos". Pela demora pensei que a revista tinha desistido do artigo. Uma crítica que nunca conseguiram fazer comigo foi com relação ao oportunismo uma vez que tenho publicações com extrativismo vegetal que remonta desde 1980, seguindo a mesma linha (HOMMA, 1980; 1982a; 1982b; 1983a; 1983b; 1985; 1986).

Participei de três viagens internacionais expondo as limitações do extrativismo vegetal [Londres, Washington e Hot Springs (Zimbabwe)] em favor da necessidade de plantios e criação de alternativas econômicas. Estas opiniões desagradam os movimentos ambientais, ao contrário dos defensores, configurando um pensamento unilateral das ONGs, Instituições internacionais e de uma parte da comunidade acadêmica com relação a Amazônia, salvo exceções. Agradeço a oportunidade proporcionada pela REA em expor estas ideias, esperando que provoquem novas antíteses que sejam úteis para o desenvolvimento da região amazônica.

Julguei necessária esta explicação, pois, de 1980 a 2019 publiquei entre artigos em periódicos, livros, capítulos de livros, anais de congressos jornais

\footnotetext{
${ }^{1}$ Movimento utilizado por seguidores de Chico Mendes com a mobilização da comunidade sob a liderança do sindicato, colocando-se, com crianças, mulheres e idosos, na frente dos peões e rumando para a área que seria desmatada pelos pecuaristas, pedindo para não derrubarem.
} 
e revistas 275 títulos e 115 palestras sobre o tema do extrativismo vegetal. A apresentação das palestras de teses, em geral, esgota-se, com três ou cinco apresentações, a minha tem permanecido até o presente, sendo, talvez, a mais debatida da UFV. As figuras que ilustram a tese apareceram em dezenas de teses e dissertações mundo afora. Isto ajuda a contextualizar as ideias que seguem de forma resumida, mencionando alguns pontos da economia extrativa, ações concretas para transformar a biodiversidade em riqueza e temas relevantes de pesquisa para estudantes de pós-graduação.

\section{O extrativismo vegetal como ciclo econômico}

O extrativismo é um ciclo constituído de três fases distintas (Figura 1) baseado na coleta de partes úteis das plantas (fruto, folha, casca, raízes, etc.), caça, pesca e extração mineral. Na primeira fase, verifica-se um crescimento na extração, quando os recursos naturais são transformados em bens úteis ou em recursos econômicos com o aumento da demanda. Na segunda fase, atinge-se o limite da capacidade de oferta, em face dos estoques disponíveis, no aumento no custo da extração, uma vez que as melhores áreas tornamse cada vez mais difíceis. Na terceira fase, inicia-se o declínio na extração, com o esgotamento das reservas ou da depredação e, com o aumento na demanda, induz o início dos plantios ou da criação, aparecimento de substitutos (sintéticos ou naturais) desde que a tecnologia de domesticação ou industrial esteja disponível, tenha utilidade ou seja viável economicamente.

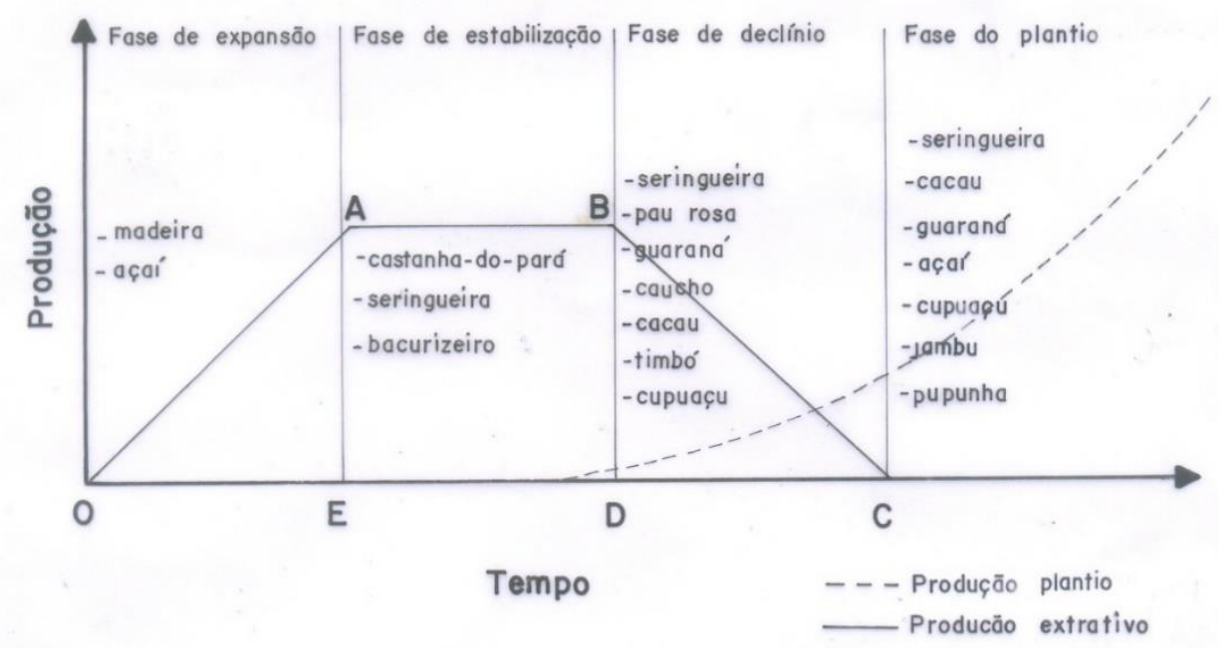

Figura 1. Ciclo do extrativismo vegetal na Amazônia (HOMMA,1980).

Esta dinâmica pode ser ilustrado em um modelo de curvas de oferta e demanda, quanto a elasticidade, deslocamento e quanto a forma de extração, que dispensamos de incluir por razões de espaço. Por esta mesma razão não são comentados aspectos da pobreza rural amazônica (renda per capita, IDH, contingente de integrantes de transferências governamentais, eletrificação rural, baixo nível de educação formal, etc.) e reduzida oferta 
tecnológica que favorecem a permanência do extrativismo vegetal e de práticas agrícolas não sustentáveis (AMIN, 1997; HOMMA, 2017).

A expansão da fronteira agrícola, a criação de alternativas econômicas, o aumento da densidade demográfica, o processo de degradação, o aparecimento de produtos substitutos, são, também, outros fatores indutores desse declínio.

A sustentabilidade do extrativismo vegetal é afetada, também, pela legislação trabalhista e, da urbanização, onde a população rural vem perdendo o seu contingente em termos relativos e absolutos, aumentando o custo de oportunidade da mão de obra no meio rural. Dependendo do processo de extração e da degradação ou para plantas de ciclo curto, a forma trapezoidal da Figura 1 pode ser alterada para uma forma triangular ou passar diretamente para plantios. Subsídios governamentais ou formas de comercio justo podem prolongar a economia extrativa.

A dispersão dos recursos extrativos na floresta faz com que a produtividade da mão de obra e da terra seja muito baixa, fazendo com que essa atividade seja viável pela inexistência de opções econômicas, de plantios ou de substitutos sintéticos. Na medida em que alternativas são criadas e as conquistas sociais elevem o valor do salário mínimo torna-se inviável a sua permanência. Um dos erros dos defensores da opção extrativa para a Amazônia é considerar esse setor como sendo isolado dos demais segmentos da economia.

A economia extrativa está embutida dentro de um contexto muito mais amplo do que é tradicionalmente analisado. Em geral, a sequência consiste na descoberta do recurso natural, extrativismo, manejo, domesticação e, para muitos, na descoberta do sintético (Figura 2). No caso do extrativismo do pau rosa (Aniba rosaeodora Ducke) e do pau brasil (Caesalpinia echinata Lam.), por exemplo, passou diretamente do extrativismo para a descoberta do sintético (HOMMA, 1992; 2018).

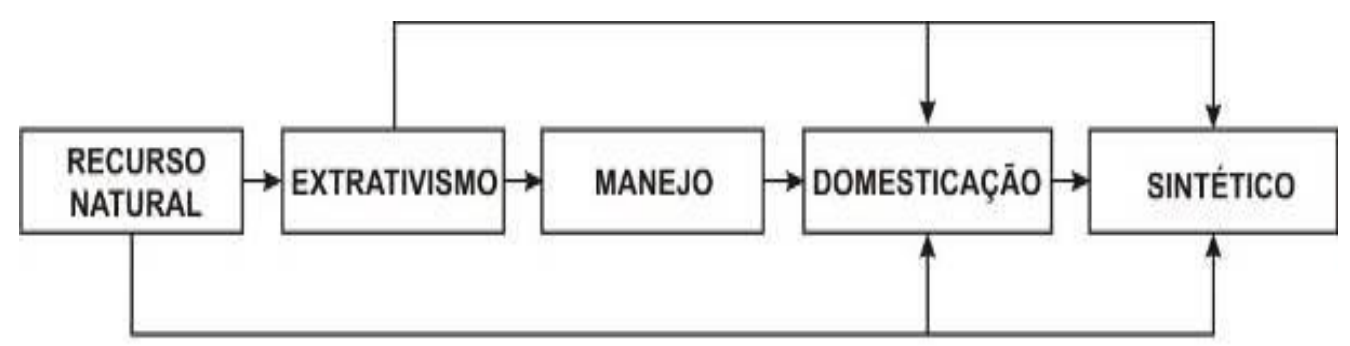

Figura 2. Possíveis formas de utilização do recurso natural depois da transformação em bem útil ou recurso econômico (HOMMA, 2008; 2012).

O extrativismo do pau-brasil constituiu o primeiro ciclo econômico do país e que perdurou por mais de três séculos, e o início do esgotamento dessas reservas coincidiu com uma série de descobertas pelos químicos alemães iniciados por Otto Unverdorben (1806-1873) em 1826 e, concluído pelo britânico William Henry Perkin (1838-1907) em 1853, iniciando a produção 
comercial de anilina (JOHNSTON, 2008). Outros produtos extrativos têm sido afetados com a substituição por produtos sintéticos, como a cesta para transporte de frutos de açaí confeccionada com talos de arumã (Ischnosiphon ovatus Kcke.), planta da família das Marantáceas, por cestas de plásticos imitando a natural, linalol sintético (essência de pau-rosa), DDT [timbó (Derris urucu Killip \& Smith, Derris nicou Benth)], chicles sintéticos, borracha sintética (3/4 do consumo mundial de borrachas), entre outros exemplos (HOMMA, 1996).

Há necessidade de apressar e/ou reverter a rota tradicional demorada dos primeiros plantios (ou criações) pelos indígenas ou pelas populações tradicionais aproveitando as plantas com as melhores características de interesse para as instituições de pesquisa. Com o progresso da biotecnologia e da engenharia genética é possível que os recursos naturais possam ser domesticados ou sintetizados diretamente da natureza sem passar pela fase extrativa ou manejada. Se este avanço se concretizar reduz as chances quanto à revitalização da economia extrativa, com a descoberta de novos recursos potenciais, principalmente fármacos, inseticidas naturais e aromáticos.

A partir da década de 1990 surgiram diversos cosméticos utilizando plantas da biodiversidade amazônica, traduzindo a ideia da força da natureza e de preservação da floresta amazônica, bastante pontuais, da condição liliputiana² e subsidiados (HOMMA, 2008; 2018). A grande questão é se esses novos produtos vão ser tão populares como o Leite de Rosas desenvolvido pelo seringalista amazonense Francisco Olympio de Oliveira (1878-1961) em 1929 e do Leite de Colônia desenvolvido pelo médico, farmacêutico e advogado Arthur Pereira Studart (1886-1969), em 1948, no Rio de Janeiro.

A fabricação de fitoterápicos e cosméticos e de outros ingredientes, que constitui a utopia de muitas propostas do aproveitamento da biodiversidade na Amazônia, que além de demandar grandes custos de pesquisa e de testes, esbarra na Lei 13.123/2015 e no Decreto 8.772/2016 que dispõe sobre o patrimônio genético, a proteção e o acesso ao conhecimento tradicional associado a repartição de benefícios e a transferência de tecnologia para a sua conservação e utilização. Esta legislação é um atraso para o desenvolvimento das pesquisas com a biodiversidade amazônica. Há necessidade de sua reformulação (ALVES et al., 2018; BOCKMANN et al., 2018).

É de se questionar se realmente existem estas mega oportunidades em se apoiar apenas no procedimento tradicional de coleta extrativa restrito ao mercado da angústia (PRADAL, 1979), com a venda de chás, infusões e garrafadas, das vendedoras da Feira do Ver-o-Peso e de outros locais similares, com apelo folclórico e turístico. A inovação mercadológica

\footnotetext{
2 Relativo a Lilipute ou o habitante desta ilha imaginária do romance Viagens de Gulliver, do escritor inglês Jonathan Swift (1667-1745), onde os habitantes medem apenas seis polegadas.
} 
constituiu na inclusão no tratamento de doenças desconhecidas no passado (colesterol, próstata, triglicerídeos, cânceres etc.).

\section{O fenômeno da domesticação}

A humanidade iniciou a domesticação de plantas e animais nos últimos dez mil anos, tendo obtido sucesso com mais de três mil plantas e centenas de animais que fazem parte da agricultura mundial. Desde quando Adão e a Eva provaram a primeira maçã (Malus domestica) extrativa no Paraíso, o Homem verificou que não poderia depender exclusivamente da caça, pesca e coleta de produtos da natureza.

A domesticação começa na seleção efetuada pelos próprios coletores observando as características úteis e, dependendo do crescimento do consumo, tende a avançar para plantios, até mesmo em uma situação de completa ausência de pesquisa (LEAKEY \& NEWTON, 1994; MAZOYER \& ROUDART, 2010; HOMMA, 2014). Por outro lado, existem plantas nas quais a domesticação tende a ser bastante difícil como o de uxizeiro [Endopleura uchi (Huber) Cuatrecasas] com baixa e lenta taxa de germinação, dificuldade no processo de enxertia e do tempo para a entrada do processo produtivo. Em outras situações, a intervenção da pesquisa se torna necessária, como foi o caso da domesticação da pimenta longa (Piper hispidinervium), planta nativa existente no Acre, de cujas folhas se descobriu o safrol. Sem o plantio é totalmente impossível a sua exploração.

É paradoxal afirmar que o capital extrativo (se tem no mato para que plantar) funciona como barreira para a domesticação induzindo o plantio em novos locais, como o cacaueiro e a seringueira, nos países asiáticos e africanos, que se tornaram em maiores produtores. São Paulo, Bahia, Espírito Santo, Minas Gerais, Paraná, Santa Catarina constitui o destino de plantas amazônicas como o cacaueiro, guaranazeiro (Paullinia cupana HBK), pupunheira (Bactris gasipaes $\mathrm{HBK})$ e seringueira.

Quando os ingleses procederam à domesticação da seringueira no Sudeste asiático, efetuando-se a segunda experiência bem-sucedida da biopirataria na Amazônia, foi como se tivesse desligado um eletrodoméstico da corrente elétrica. Esse caminho tinha sido seguido com o tomateiro (Lycopersicon esculentum Mill.) e a batata inglesa (Solanum tuberosum) ambas da cordilheira dos Andes, fumo (Nicotiana tabacum), milho (Zea mays L), cinchona (Chinchona calisaya Wedd, C. ludgeriana R. et P.), transformando em cultivos universais pelos colonizadores europeus. De forma inversa, muitas plantas de origem africana, como o cafeeiro (Coffea arabica L.) e, o eucalipto (Eucalyptus spp.)], de origem australiana, tiveram a domesticação efetuada no país e tornamos nos maiores produtores mundiais.

No caso de produtos extrativos com grande importância econômica, o caminho inevitável é a domesticação, o manejo ou a descoberta de substitutos sintéticos. A domesticação do jaborandi (Pilocarpus microphyllus Statf.) e o início da domesticação da fava d'anta (Dimorphandra gardeniana e D. mollis Benth), iniciada pela extinta Merck (atual Quercegen Agronegócios I Ltda.), podem ser considerados exemplos desse caso. 
O exemplo do jambu (Acmella oleracea L.) que contém o alcaloide spilanthol nas folhas, ramos e flores é descrito em patentes como apropriado para uso anestésico, antisséptico, creme dental, ginecológico e anti-inflamatório é utilizado pela Natura na composição de creme antirrugas Chronos. Antes adquirida na Região Metropolitana de Belém, a partir de 2004, passou a ser fornecido pelo Grupo Centroflora, fundado em 1957, de produtores selecionados que cultivam de forma orgânica nos municípios de Pratânia, Botucatu, Ribeirão Preto e Jaboticabal. Esta é a razão da existência de 433 pedidos de patentes até 06/2018 relacionados com o jambu. Japão com 137 pedidos (32,16\%), Estados Unidos 102 (23,94\%), França 55 (12,91\%), Espanha $36(8,54 \%)$, China $26(6,10 \%)$, Brasil $15(3,52 \%)$, Alemanha 10 $(2,35 \%)$, Inglaterra $7(1,64 \%)$ que se encontram registrados no United States Patent and Trademark Office (USPTO), World Intellectual Property Organization (WIPO) e Instituto Nacional de Propriedade Intelectual (INPE) (PATENTE ..., 2018).

Existem plantas e animais que nunca serão domesticados, por não terem importância econômica, devido ao longo tempo necessário para obtenção do produto, à existência em grandes estoques ou da dificuldade de sua domesticação. O babaçu que já foi à base da economia do Maranhão até a década de 1950, apresenta três espécies: a) Attalea speciosa Mart. ex Spreng trata-se do babaçu strictu sensu, é a de maior distribuição, variação morfológica e importância econômica, formando povoamentos extensivos no Maranhão, Piauí, Goiás, Tocantins e Mato Grosso e também na Bolívia e no Suriname; b) Attalea eichleri (Drude) A.J. Hend - palmeira acaule, com cachos e frutos pequenos; c) Attalea eichleri $x$ speciosa Pabst - planta com características intermediárias entre as espécies anteriores, por ser um híbrido oriundo do cruzamento natural dessas duas espécies. É importante o desenvolvimento de pesquisas visando ao seu plantio em escala comercial deste híbrido (VENTURIERI et al., 2017; PINHEIRO et al., 2005).

No caso de animais, o processo de domesticação tende a ser orientado para as características que facilitam a coexistência com o homem, comportamento sexual promiscuo, interação adulto-jovem e facilidade de alimentação. Mesmo animais de difícil domesticação, como o cultivo de ostras para produção de pérolas (Pinctada sp.), avestruz (Struthio camelus), codornas (Coturnix coturnix), peixes, camarões de água salgada (Penaeus sp), camarões de água doce (Macrobrachium rosenbergii) são obtidos em criações, ampliando a oferta e oferecendo a preços mais reduzidos (HOMMA, 2008). Muitas drogas, como a maconha (Cannabis sativa) e coca (Erythroxylum coca Lam.) são plantadas e, a sua destruição criativa seria descobrir pragas e doenças que possam prejudicar o seu desenvolvimento (HOMMA, 1980; 1992; 2012).

Na Amazônia das centenas de frutas nativas existentes, vários são produtos extrativos invisíveis, sem importância econômica definida, somente alguns sofrerão o processo de domesticação (CAVALCANTE, 2010). Enquanto existirem estoques dessas plantas na natureza e compensarem a utilização da mão de obra para a sua coleta, a atividade extrativa pode perpetuar, pelo menos até que alguma força externa afete esse equilíbrio. Em outras 
situações pode prevalecer o dualismo tecnológico, com o extrativismo vegetal ou animal convivendo com o sistema domesticado, de forma temporária ou permanente (PAIVA, 1975).

O extrativismo de diversas plantas ou insetos utilizados como corantes como o pau-brasil, anil (Indigofera tinctoria L.), cochonilha (Dactylopius coccus) e carageru (Arrabidaeae chica H.B.K.) desapareceram com a descoberta da anilina e de outros corantes sintéticos (CARREIRA, 1988). O extrativismo do babaçu perdeu a sua importância com a expansão do cultivo de grãos como a soja (Glycine max L. Merrill), milho, algodão (Gossypium herbaceum) com a obtenção de óleo para cozinha e da expansão da fronteira agrícola. $\mathrm{O}$ atual aproveitamento do babaçu se destina a nichos de mercados, como cosméticos, no discurso da inclusão social e a criação de babaçuais livres, permitindo o seu acesso nas propriedades privadas.

O extrativismo de plantas medicinais como a salsaparrilha-do-pará (Smilax papiracea) que era utilizado para o tratamento de sífilis, a cinchona para tratamento de malária, etc. foram substituídas com o progresso da indústria farmacêutica e da medicina. A patente do Viagra, em 1996, que se seguiram à do Levitra e Cialis, ambos em 2003, para a cura da impotência masculina tem reduzido a matança de animais e de plantas empregadas na medicina tradicional e popular na Ásia, cujo comportamento precisa ser comprovadas na Amazônia (VON HIPPEL \& VON HIPPEL, 2002).

Algumas plantas semidomesticadas podem reverter para a forma extrativa, como a seringueira, a baunilha (Vanilla spp), a castanheira ou a introdução de espécies domesticadas em ambientes extrativos (erva mate). Com o Novo Código Florestal poderá induzir a redução de áreas agrícolas e de pastos estimulando a reversão do plantio domesticado para extrativismo visando o aproveitamento de Áreas de Reserva Legal e Áreas de Preservação Permanente, com geração de renda. No futuro, novas plantas e animais da Amazônia serão domesticados (BORÉM et al., 2009). Com o processo de domesticação, consegue-se ampliar a oferta, obter um produto de melhor qualidade e a preços mais reduzidos, beneficiando os consumidores e produtores.

\section{As políticas de manutenção do extrativismo}

A economia amazônica tem-se desenvolvido pelo aproveitamento dos recursos disponíveis na natureza. Foi o que ocorreu com a extração da borracha, da castanha-do-pará, do pau-rosa, do óleo de tartaruga, do pirarucu e, em época mais contemporânea, da madeira, do palmito e fruto de açaizeiro, da mineração, do petróleo, da energia hidráulica, entre outros produtos. O aproveitamento de recursos disponíveis na natureza, negligencia quanto ao seu esgotamento, fundamenta-se na exportação de matéria-prima, desestimula a industrialização, provoca realocação no mercado de mão de obra e afeta a economia local. Isto sintetiza claramente o modelo de Dutch Disease desenvolvido por Coorden e Neary (1982), quanto ao efeito da descoberta de reservas de gás natural no Mar do Norte 
na década de 1960, afetando a economia holandesa (BARHAM \& COOMES, 1994).

Mercados constituem a razão para a existência e o desaparecimento de economias extrativas. A transformação de um recurso natural em produto útil ou econômico é o primeiro passo da economia extrativa. Contudo, à medida que o mercado começa a expandir, as forças que provocam o seu declínio, também, aumentam. A limitada capacidade de oferta de produtos extrativos leva à necessidade de se efetuar o seu manejo ou o plantio e à descoberta de substitutos sintéticos ou de outro substituto natural.

Em época mais recente o conceito de bioeconomia extrativa, mantendo a "floresta em pé", enfatiza, também, quanto a transformação monetária dos serviços ambientais, com um sistema de comando e controle sem considerar a qualidade de vida das populações amazônicas. A antítese desta proposta que tem grande simpatia dos países desenvolvidos é o desconhecimento do mecanismo da economia extrativa e da importância de se modificar o perfil tecnológico da agricultura amazônica. Há um dúbio sentido da "floresta em pé": uma quanto a possibilidade de viver da coleta extrativa e, a outra, de desenvolver atividades agrícolas nas áreas já desmatadas evitando a pressão sobre a floresta.

A dinâmica do extrativismo vegetal que conduz a forma trapezoidal (Figura 3), pode apresentar sucessivos deslocamentos desse ciclo ao longo do tempo e para determinada área geográfica. Foi o que ocorreu na Amazônia em épocas sucessivas com a fase das "drogas do sertão", do extrativismo do cacau, seringueira, castanha-do-pará, pau-rosa, entre outros. No caso do extrativismo da madeira, que tem sido considerado em termos agregados, na verdade, ela se constitui de dezenas de espécies madeireiras. No apogeu da extração madeireira nas décadas de 1970 a 1990 se caracterizou pela extração das espécies mais nobres, como mogno (Swietenia macrophylla King), passando com o seu esgotamento, para madeiras de segunda e terceira categorias.

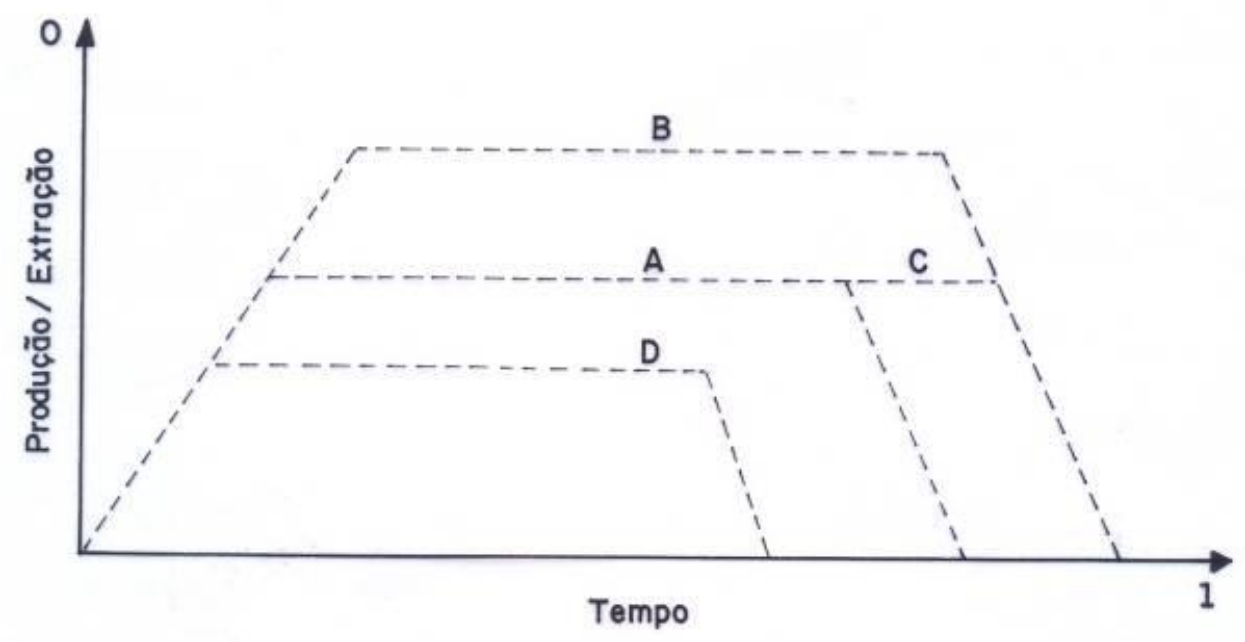

Figura 3. Possibilidades de mudanças no ciclo do extrativismo vegetal por estimulo de políticas governamentais (HOMMA, 1996). 
Nesse contexto, a bioeconomia extrativa seria a de tentar prolongar a vida do extrativismo (B e C) (Figura 3), em alguma das três fases mencionadas anteriormente (Figura 1). Mas pode ocorrer o inverso (D), induzindo à redução da vida útil da economia extrativa se forem introduzidas novas opções econômicas. Muitas das acepções como neo-extrativismo, bioextrativismo, extrativismo sustentável orgânico, bioeconomia extrativa, sociobiodiversidade são sósias temáticas para manter o extrativismo com subsídios diretos e indiretos, que, podem ser vítimas do seu próprio sucesso (REGO, 1999; HOMMA, 2000; HOMMA, 2018; BARROSO \& MELLO, 2020).

A manutenção do extrativismo na Amazônia exige a conservação da floresta, impedir o surgimento de atividades competitivas, a melhoria ou abertura de estradas, manter baixa densidade populacional e, sobretudo, evitar o financiamento de pesquisa de domesticação, uma vez que se tornam em indutores do seu desaparecimento. No caso da Amazônia a evidente simpatia de cientistas e ambientalistas de países desenvolvidos para a manutenção do extrativismo vegetal, pode-se criar vetores de força impedindo a domesticação, apesar dos evidentes benefícios para a sociedade.

\section{O manejo de recursos extrativos}

A importância das técnicas de manejo é de aumentar a capacidade de suporte como está ocorrendo no manejo de açaizais nativos no estuário do rio Amazonas. Para isso promovem o desbaste de espécies vegetais concorrentes, transformando em uma floresta oligárquica, como se fosse um plantio, aumentando a produtividade dos frutos e de palmito (Figura 4). Este mesmo fenômeno está ocorrendo com o manejo de rebrotamento de bacurizeiros no Nordeste Paraense e no Estado do Maranhão, induzido pelo crescimento do mercado urbano dessa fruta.

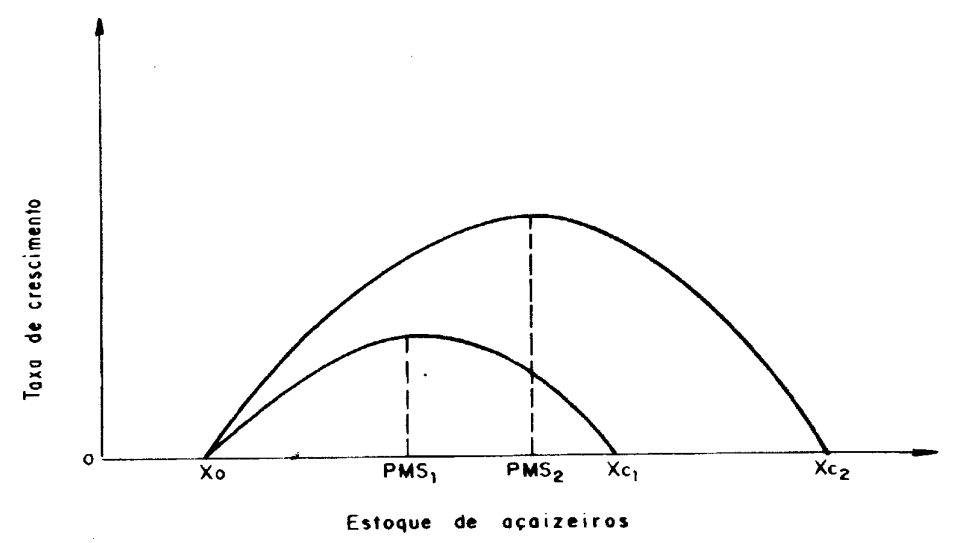

Figura 4. Modificação da capacidade de suporte decorrente do manejo de açaizais nativos (HOMMA, 2008).

O recente boom da polpa de açaí tem sido o indutor da expansão de açaizais manejadas, ampliando o consumo antes restrito ao período da safra para o ano inteiro decorrente dos processos de beneficiamento e congelamento, 
novos produtos e exportação para outras partes do país e do exterior. A lucratividade e o reduzido investimento para o manejo dos açaizais descartam o interesse dos ribeirinhos e extrativistas em criarem áreas de domínio comum, como um socialismo florestal. O levantamento do Censo Agrícola 2017 identificou 47.855 estabelecimentos agrícolas no país que declararam possuir mais de 50 pés de açaizeiros, dos quais 35.374 propriedades no Estado do Pará (73,92\%), 8.495 no Amazonas (17,75\%) e 1.901 no Amapá (3,97\%). A área manejada e plantada no Estado do Pará somava 168.546 ha com uma produção de 241.816 toneladas, perfazendo, 4,47 ha açaizeiro/propriedade, produção de 6,83 t/propriedade e renda bruta de R\$ 13.446,20/propriedade (INSTITUTO ..., 2017).

Nas atuais áreas de extração de palmito e de fruto do açaí no estuário amazônico verifica-se que a viabilidade econômica dessa atividade e da existência dos estoques de açaizais é decorrente das transformações da economia extrativa ao longo do tempo. A extração comercial do palmito de açaí iniciou-se em 1968 no município de Barcarena, Pará devido à exaustão de estoques de juçara (Euterpe edulis Mart.) nos remanescentes da Mata Atlântica. Essa palmeira tem como característica de não apresentar rebrotamento após o corte. Deve ser ressaltado que a paisagem no estuário amazônico onde ocorrem os açaizais vem apresentando continua mudança desde o século XVII. No passado, a extração de ucuúba (Virola surinamensis, Myristica sebifera), andiroba (Carapa guianensis Aublet), resinas, breu, patauá (Jessenia bataua), cacau, murumuru (Astrocaryum murumuru), pracaxi (Pentaclethra filamentosa), jutaicica, látex de maçaranduba [Manilkara huberi (Ducke) Stand.], tiveram grande importância relativa em comparação com a extração atual de palmito e fruto de açaí (NOGUEIRA 1997). A extração de madeira teve forte impacto ao longo dos séculos, favorecendo a formação de estoques mais homogêneos de açaizeiros. A extração de borracha também provocou modificações na paisagem desde o início do "boom" e durante a II Guerra Mundial.

\section{Agenda para pesquisa}

Procura-se listar alguns temas de pesquisa voltados para a economia extrativa. Há muita desinformação e visão parcial sobre a Amazônia. A reduzida oferta técnica e científica, a despeito do avanço atingido, alimenta estas especulações.

Para transformar a biodiversidade amazônica em riqueza não será estimulando a coleta extrativa, mesmo com avançados processos de verticalização propostos nos acrônimos 4.0 (NOBRE \& NOBRE, 2019; BARROSO \& MELLO, 2020). Há necessidade de estimular as pesquisas com a domesticação de espécies potenciais da flora e da fauna amazônica. Muitas destas espécies estão em extinção, em perigo ou vulneráveis. Benefícios sociais da domesticação, do valor da biodiversidade e do custo social da destruição dos recursos da biodiversidade podem ser efetuados comparando-se a oferta extrativa versus a de plantios (seringueira, cacaueiro, guaranazeiro, etc.). $\mathrm{O}$ inverso pode ser verificado no caso da 
introdução da biodiversidade exótica e dos benefícios sociais da imigração transferindo estes recursos genéticos.

Como a legislação trabalhista está afetando os sistemas de produção agrícola no país e quais os efeitos para a economia extrativa de uma atividade com baixa produtividade da terra e da mão de obra? Qual a razão da permanência mesmo sendo atividades com baixa rentabilidade? Atividades com dificuldade para a mecanização em alguma parte do processo produtivo devido a desafios tecnológicos (máquina para sangrar a seringueira, colhedeira de açaí, quebradeira de babaçu, despolpadeira para bacuri, etc.) tornam mais competitivos para os pequenos produtores? Quais os efeitos da Lei 14.119 (13/1/2021) que criou a Política Nacional de Pagamentos por Serviços Ambientais (PNPSA) e do Decreto $n^{0} 10.623$ (9/2/2021) que instituiu o Programa Adote um Parque nas unidades de conservação federais?

A ênfase na tragédia dos comuns mencionada nos estudos sobre a economia extrativa precisa avançar utilizando a tragédia dos anticomuns e do Dutch Disease (HARDIN, 1968; HELLER, 1998; BARHAM \& COOMES, 1993). As influências das taxas de juros, estruturas de mercados, direitos de propriedade, produtos com demanda elástica e a domesticação, Unidades de Conservação versus a preservação e concepção de sustentabilidade de Produto Florestal Não Madeireiro, são sugestões de temas de pesquisa para os estudantes de pós-graduação (EL SERAFY, 1989). Desenvolver pesquisas sobre mercados de produtos extrativos como açaí, castanha do pará, polpa de bacuri, tucumã, etc. in natura, com beneficiamento primário e novos produtos. Análise de produção/consumo per capita dos extrativistas e consumidores urbanos, diferenças nos custos de produção extrativa e plantada como decorrentes do custo de insumos ou de variáveis ambientais, entre outros, revelam como sendo importantes (PEARSON et al, 1987; VERA FILHO, 1979; OSTROM, 2020).

Cada produto extrativo apresenta situações distintas quanto a sua história, botânica, grau de domesticação, processo de extração, beneficiamento, comercialização, utilização, entre outros, que exige análise diferenciada. Implicações da economia extrativa versus REDD + e outros mecanismos de transformação monetária dos serviços ambientais, dos custos sociais da política de preços mínimos dos produtos da sociodiversidade ${ }^{3}$, da COVID 19, entre outros, são macros temas que merecem análise. O conflito entre as políticas conservacionistas e a sustentabilidade social e ambiental é patente.

É importante a análise do processo histórico da perda de importância da economia extrativa vegetal e animal como processo de desenvolvimento com base em um produto principal, na concepção da staple theory, de Melville H. Watkins (1932-2020) (WATKINS, 1963). Isto ocorreu no passado com o pau brasil, borracha, babaçu, castanha do pará, madeira, no contexto

${ }^{3}$ Política de Garantia de Preços Mínimos para os Produtos da Sociobiodiversidade (PGPMBio) garante um preço mínimo para 17 produtos extrativistas: açaí, andiroba, babaçu, baru, borracha extrativa, buriti, cacau extrativo, castanha do pará, carnaúba, juçara, macaúba, mangaba, murumuru, pequi, piaçava, pinhão e umbu. 
local, regional e nacional. Talvez o setor mineral vem desempenhando este papel na atualidade.

Finalmente, outro tema está associado com a criação de mecanismos de controle baseado em prerrogativas de direitos humanos, proteção de ecossistemas e da biodiversidade, atividades sustentáveis e desenvolvimento local. Estes mecanismos controladas por ONGs ou entidades internacionais impõe limites de desenvolvimento considerados adequados por uma ótica externa.

\section{Conclusões}

O extrativismo vegetal na Amazônia foi muito importante no passado, é importante no presente, mas há necessidade de pensar sobre o futuro da região. Foi o extrativismo da seringueira que permitiu o povoamento da região, a construção de infraestrutura produtiva, sustentou a economia nacional por três décadas como terceiro produto de exportação vindo depois do café e algodão e promoveu a anexação do Acre à soberania nacional. Há necessidade do Brasil atingir a autossuficiência na produção borracha natural e não será através da borracha extrativa.

A economia extrativa foi à razão e a causa do atraso regional e da sua destruição (madeira), apoiando-se na disponibilidade dos recursos naturais, na crença da sua inesgotabilidade. Dessa forma, o culto ao atraso, de muitas propostas ambientais, tanto nacionais como estrangeiras, em favor do extrativismo na Amazônia, escondem resultados que podem ser avessos aos interesses dos consumidores, das indústrias e dos próprios extratores.

Para a manutenção do extrativismo é importante que não se criem alternativas de renda e emprego, a melhoria da infraestrutura, impedir as pesquisas com a domesticação das plantas e animais passíveis de serem incorporadas ao processo produtivo, daí o obscurantismo de muitas propostas ambientais defendidas pelos países desenvolvidos para a Amazônia. A extração pulverizada e a inexistência de economia de escala tornam um grande desafio como um modelo adequado para a Amazônia.

Ao contrário do propalado, a criação de reservas extrativistas nem sempre constitui em garantia da conservação e preservação dos recursos naturais. Apesar da ênfase no manejo, a exploração de muitos recursos extrativos tende levar a sua exaustão, na destruição da floresta e mudando para novos locais. A extração madeireira comunitária, a criação bovina e atividades de roça poderão levar a uma reserva extrativista sem extrativismo no futuro. Para evitar desmatamentos e queimadas na Amazônia vai depender do aproveitamento parcial dos 78 milhões de hectares já desmatados (2019), com atividades produtivas adequadas e promovendo a recuperação de áreas que não deveriam ter sido desmatadas. Neste elenco encaixa-se um conjunto de produtos da biodiversidade do passado, do presente e aqueles por descobrir que precisamos plantar. 
Para os produtos extrativos alimentícios que apresentem conflitos entre a oferta e a demanda é urgente promover a sua domesticação. A implementação do Código Florestal conduzindo a recuperação de ecossistemas destruídos pode induzir ao desenvolvimento de sistemas híbridos envolvendo plantios convertidos em extrativos ou manejados para recompor Áreas de Reserva Legal e Áreas de Preservação Permanente.

Justifica-se a manutenção do extrativismo como uma maneira de comprar tempo, enquanto não surgirem alternativas, para evitar o êxodo rural ou quando existirem em grandes estoques. A formação de um parque produtivo com a domesticação de plantas extrativas atualmente conhecidas e àqueles potenciais é a melhor garantia para evitar a biopirataria na Amazônia e dos países vizinhos e de gerar renda e emprego. Políticas em favor de produtos extrativos, devido a restrições na oferta e no custo, poderão estimular plantios, sustentar mediante subsídios ou mudança para outras atividades.

\section{Referências}

ALLEGRETTI, M.H.; CUNHA, L.H.O.; SCHMINK, M. Edição especial 30 anos do legado de Chico Mendes. Desenvolvimento e Meio Ambiente, Curitiba, v.48, p.1-6, nov. 2018.

ALMEIDA, M.W.B.; ALLEGRETTI, M.H.; POSTIGO, A. O legado de Chico Mendes: êxito e entraves das Reservas Extrativistas. Desenvolvimento e Meio Ambiente, Curitiba, v.48, p.25-55, nov. 2018.

ALVES, R.J.V. et al. Brazilian legislation on genetic heritage harms Biodiversity Convention goals and threatens basic biology research and education. Anais da Academia Brasileira de Ciências, Rio de Janeiro, v.90, n.2, p.1279-1284, 2018.

AMIN, M.M. O extrativismo como fator de empobrecimento da economia do Estado do Pará. In: XIMENES, T. (Org.). Perspectivas do desenvolvimento sustentável: uma contribuição para a Amazônia. Belém, PA: UFPa, NAEA: UNAMAZ, 1997. p.177-209.

BARHAM, B.L.; COOMES, O.T. Reinterpreting the Amazon Rubber Boom: Investment, the State and Dutch Disease. Latin American Research Review, v.29, n.2, p.73-109, Dec. 1993.

BARROSO, L.R.; MELLO, P.P.C. Como salvar a Amazônia: por que a floresta de pé vale mais do que derrubada. Revista de Direito da Cidade, v. 12, n. 2, p. 331-376, 2020.

BOCKMANN, F.A. et al. Brazil's government attacks biodiversity. Science, v.360, n.6.391, p.865, 25 May 2018.

BORÉM, A.; LOPES, M.T.G.; CLEMENT, C.R. (Eds.). Domesticação e melhoramento: espécies amazônica. Viçosa, MG: Universidade Federal de Viçosa, 2009. 486.

CARREIRA, A. A Companhia Geral do Grão Pará e Maranhão. São Paulo: Ed. Nacional, 1988. 2 v. 
CAVALCANTE, P. Frutas comestíveis na Amazônia. Belém, PA: MPEG, 2010. $280 \mathrm{p}$.

CORDEN, W. M.; NEARY, J. P. Booming sector and de-industrialisation in a small open economy. Economic Journal, Cambridge, v. 92, n. 368, p. 825848, Dec. 1982.

EL SERAFY, J. The proper calculation of income from depletable natural resources. In: AHMAD, Y.; EL SERAFY, S.; LUTZ, E. (Eds.). Environmental and natural resource accounting and their relevance to the measurement of sustainable development. Washington, D.C.: World Bank/UNEP, 1989. p.1018.

HARDIN, G. The tragedy of the commons. Science, v. 162, p. 1243-1248, Dec. 1968.

HELLER, M.A. The tragedy of the anticommons: property in the transition from Marx to markets. Harvard Law Review, v.111, n.3, p.621-688, Jan. 1998.

HOMMA, A. Deixem Chico Mendes em Paz. Veja, São Paulo, v.23, n.50, p.106, 19 dez. 1990.

HOMMA, A. K. O. Amazônia: os limites da opção extrativa. Ciência Hoje, Rio de Janeiro, v. 27, n. 159, p. 70-73, abr. 2000.

HOMMA, A. K. O. Extrativismo, biodiversidade e biopirataria: como produzir benefícios para a Amazônia. Brasília, DF: Embrapa Informação Tecnológica; Belém, PA: Embrapa Amazônia Oriental, 2008. 97 p. (Texto para Discussão, 27).

HOMMA, A. K. O. Plant extractivism or plantations: what is the best option for the Amazon? Estudos Avançados, São Paulo, v. 74, n. 26, p. 167-186, 2012.

HOMMA, A. K. O. The dynamics of extraction in Amazon: a historical perspective. In: NEPSTAD, D. C.; SCHWARTZMAN, S. (Eds.). Non-timber products from tropical forests: evaluation of a conservation and development. New York: New York Botanical Garden, 1992. p. 23-31.

HOMMA, A.K.O. (Ed.). Extrativismo vegetal na Amazônia: história, ecologia, economia e domesticação. Brasília, DF: Embrapa, 2014. 468p.

HOMMA, A.K.O. A Extração de Recursos Naturais Renováveis: o Caso do Extrativismo Vegetal na Amazônia. 1989. 575 f. Tese (Doutorado em Economia Rural) - Universidade Federal de Viçosa, Viçosa, MG.

HOMMA, A.K.O. A incerteza na dimensão real dos recursos naturais como fator de depredação. Boletim FBCN, Rio de Janeiro, n. 21, p. 86-93, 1986.

HOMMA, A.K.O. A terceira natureza da Amazônia. Revista Paranaense de Desenvolvimento, Curitiba, v.38, n.132, p.27-42, jan./jun. 2017.

HOMMA, A.K.O. Colhendo da natureza: o extrativismo vegetal na Amazônia. Brasília, DF: Embrapa, 2018. 219p.

HOMMA, A.K.O. Esgotamento dos recursos finitos: o caso do extrativismo vegetal na Amazônia. Boletim FBCN, Rio de Janeiro, n. 18, p. 44-48, 1983a. 
HOMMA, A.K.O. Intocabilidade, exploração econômica e depredação dos recursos naturais: o caso do extrativismo vegetal na Amazônia. Boletim FBCN, Rio de Janeiro, n. 20, p. 10-26, 1985.

HOMMA, A.K.O. Modernization and technological dualism in the extractive economy in Amazonia. In: PÉREZ, M.R.; ARNOLD, J.E.M. (Eds.). Current issues in non-timber forest products research. Bogor, Indonesia, CIFOR/ODA, 1996. p.59-81.

HOMMA, A.K.O. Tentativa de interpretação do extrativismo amazônico. Cadernos NAEA, Belém, PA, n. 7, p. 39-51, 1983b.

HOMMA, A.K.O. Uma tentativa de interpretação teórica do extrativismo amazônico. Acta amazonica, Manaus, v. 12, n. 2, p.251-255, 1982a.

HOMMA, A.K.O. Uma tentativa de interpretação teórica do extrativismo amazônico. In: SIMPÓSIO SOBRE SISTEMAS DE PRODUÇÃO EM CONSÓRCIO PARA EXPLORAÇÃO PERMANENTE DOS SOLOS DA AMAZÔNIA, 1980, Belém, PA. Anais... Belém, PA: EMBRAPA-CPATU: GTZ, 1982b. p. 255-271. (EMBRAPA-CPATU. Documentos, 7)

HOMMA, A.K.O. Uma tentativa de interpretação teórica do processo extrativo. Boletim FBCN, Rio de Janeiro, n. 16, p. 136-141, 1980.

INSTITUTO BRASILEIRO DE GEOGRAFIA E ESTATÍSTICA - IBGE. Censo Agropecuário 2017.

JOHNSTON, W.T. The discovery of aniline and the origin of the term "aniline dye". Biotechnic \& Histochemistry, v.83, n.2, p. 83-87, 2008.

LEAKEY, R. R. B.; NEWTON, A. C. Domestication of tropical trees for timber and non-timber products. MAB Digest, Paris, Unesco, v.17, 1994. 94p.

MAY, P.H. A modern tragedy of the non-commons: agro-industrial change and equity in Brazil's babassu palm zone. 1986. $432 \mathrm{f}$. Tese (Doutorado) - Cornell University, New York.

MAZOYER, M.; ROUDART, L. História das agriculturas no mundo: do neolítico à crise contemporânea. São Paulo: Editora UNESP; Brasília, DF: NEAD, 2010. 568p.

NOBRE, I.; NOBRE, C. Projeto “Amazônia 4.0": Definindo uma Terceira Via para a Amazônia. Futuribles, São Paulo, n.2, p.7-20, set. 2019.

NOGUEIRA, O. L. Regeneração, manejo e exploração de açaizais nativos de várzea do estuário amazônico. 1997. 149 f. Tese (Doutorado em Ciâncias Biológicas) - Universidade Federal do Pará, Belém, PA.

OSTROM, E. Beyond Markets and States: Polycentric Governance of Complex Economic Systems. Prize Lecture, December 8, 2009. Disponível em <https:/ / www.nobelprize.org/uploads/2018/06/ostrom_lecture.pdf>. Acesso em 11 abril 2020.

PAIVA, R.M. Modernização e dualismo tecnológico na agricultura: uma reformulação. Pesquisa e Planejamento Econômico, v. 5, n. 1, p. 117-161, jun. 1975. 
PATENTE do jambu não impede pesquisas. O Liberal, Belém, 30 jun. 2018. p.4.

PEARSON, S.R.; AVILLEZ, F.; BENTLEY, J.W. (Eds). Portuguese agriculture in transition. Ithaca, NY, Cornell University, 1987.

PINHEIRO, C.U.B.; FRAZÃO, J.M.F.; BALICK, M.J. Coleta de germoplasma de palmeiras do complexo babaçu (Orbignya e Attalea). In: WALTER, B.M.T.; CAVALCANTI, T.B. (Eds.). Fundamentos para a coleta de germoplasma vegetal. Brasília, DF: Embrapa Recursos Genéticos e Biotecnologia, 2005. p. 549-583.

PRADAL, H. Mercado da angústia. São Paulo: Paz e Terra, 1979.

REGO, J. F. do. Amazônia: do extrativismo ao neoextrativismo. Ciência Hoje, v. 25, n. 147, p. 62-65, mar. 1999.

VENTURIERI, A. et al. Potencialidade agrícola de municípios ao longo da ferrovia Carajás-Itaqui, entre Santa Inês e São Luís, MA. Belém: Embrapa Amazônia Oriental, 2017. (Documentos. Embrapa Amazônia Oriental, 433). 129p.

VERA FILHO, F.R.P. Ganhos tecnológicos via redução da heterogeneidade produtiva entre empresas agrícolas. Revista de Economia Rural, Brasília, v.17, n.3, p:85-92, jul./set.1979.

VON HIPPEL, W.; VON HIPPEL, F. A. Sex, drugs, and animal parts: will Viagra save threatened species? Environmental Conservation, v. 29, n. 3, p. 277-281, 2002.

WATKINS, M.H. A Staple theory of economic growth. The Canadian Journal of Economics and Political Science, v. 29, n. 2, p. 141-158, May 1963. 